TAPROBANICA, ISSN 1800-427X. April, 2020. Vol. 09, No. 01: pp. 31-38, pls. 12-14. (C) Research Center for Climate Change, University of Indonesia, Depok, Indonesia www.taprobanica.org

\title{
ON TWO POORLY KNOWN, INSULAR SKINKS, Eutropis tytleri (THEOBALD, 1868) AND E. andamanensis (SMITH, 1935) (REPTILIA: SCINCIDAE), ENDEMIC TO THE ANDAMAN ISLANDS, INDIA
}

\author{
S. R. Chandramouli ${ }^{1}$ \& A. A. Thasun Amarasinghe $e^{2,3}$ \\ ${ }^{1}$ Department of Ecology and Environmental Sciences, School of Life Sciences, Pondicherry University, \\ Puducherry, India \\ ${ }^{2}$ Research Center for Climate Change, University of Indonesia, Gd. PAU Lt. 8.5, Kampus UI, Depok 16424, \\ Indonesia \\ ${ }^{3}$ Association of Asian Herpetology (Asosiasi Herpetologi Asia), Jl. BSD Bintaro No. 88, Pondok Aren 15228, \\ Tangerang Selatan, Indonesia \\ ${ }^{1}$ Corresponding author. E-mail: findthesnakeman@gmail.com
}

\begin{abstract}
We examined the holotype of Eutropis tytleri and one of the syntypes of E. andamanensis collected from the Andaman Islands, currently deposited at the Zoological Survey of India (ZSI). Information on taxonomy, morphology, distribution, behaviour and natural history of these two poorly-known, insular endemic skinks are presented here based on individuals recorded and examined in-situ, in the field as well as preserved material. Their types are illustrated and redescribed. A distribution map is presented based on records from the present study; threats and conservation status are discussed.
\end{abstract}

Key words: Andaman grass-skink, distribution, Mabuya, natural history, Sincus, taxonomy.

\section{Introduction}

The genus Eutropis Fitzinger, 1843 in the Andaman archipelago is represented by only two species: E. tytleri (Theobald, 1868) and E. andamanensis (Smith, 1935). These species are endemic to the Andaman Islands (Das 1999, Amarasinghe et al. 2020). Although described in the 1860s and 1930s, Eutropis tytleri and E. andamanensis remain among the most poorly known species within this genus, possibly because of their narrow distribution, and the difficulty of access to the Andaman Islands. The
Andaman archipelago, located south of the Burmese peninsula is believed to be a submerged extension of the Arakan Mountains, which date back to the middle Miocene (15 Mya) with a general faunal affinity with the Indo-Chinese region (Hall 1997, Das 1999).

Theobald (1868) described Scincus tytleri based on the specimen ZSI 2273 from 'Andamans, India'. This was the first skink to be named from the Andaman Islands. Subsequently, Boulenger (1887) transferred it to Mabuia. Later, Smith (1935) in his monograph 
on lizards of the Indian subcontinent used the combination Mabuya tytleri, with the corrected generic spelling Mabuya. He also described a new species, Mabuya andamanensis, from the Andaman Islands based on two syntypes, one deposited in London: BMNH 1946.8.3.62 and the other in Kolkata: ZSI 15084. The comprehensive generic revision of skinks by Mausfeld et al. (2002) and Mausfeld and Schmitz (2004) resulted in the transfer of Mabuya tytleri and $M$. andamanensis to the genus Eutropis, the currently accepted combination.

Recent literature on Indian lizards such as Daniel (2002), Das (2002), and Das \& Das (2018) could not provide any reliable novel data on either species, but only provide anecdotal information owing to a lack of field data based on recent surveys. Hence, the present paper aims to provide additional information on various aspects of these poorly known, insular endemic species.

\section{Material and methods}

Field surveys were carried out on several islands of the Andaman Archipelago to record the target species. Individuals were observed in the field, gently restrained, measured and released at the point of capture.

We compared specimens (including types), original descriptions, and other specimens of Eutropis tytleri and E. andamanensis, as well as specimens of their congeners (Appendix 1). Museum acronyms are those of Uetz et al. (2019). We examined the external morphology of specimens by using a Wild M3Z stereomicroscope. Sex was not determined from specimens unless the hemipenes in males were everted. All locality records are based on our personal observations and data recorded in museums. Altitudes are given in meters above sea level (a.s.l.). The following measurements were taken to the nearest $0.1 \mathrm{~mm}$ on the left side of the body with a Mitutoyo digital caliper: snout-vent length (SVL, from tip of snout to anterior margin of vent), axilla-groin distance (AG, from the posterior margin of the forelimb at its insertion point on the body to the anterior margin of the hind limb at its insertion point on the body), thigh length (FEL, from the anterior margin of the hind limb at its insertion point on the body to the knee while flexed 90 degree), shank length (TBL, from the posterior surface of the knee while flexed 90 degree to the base of the heel), head length (HL, from posterior edge of the retro-articular process of the mandible to tip of snout); head width (HW, width of head at the temporo-mandibular articulation / angle of the jaws), orbit diameter (ED, the greatest horizontal diameter of the orbit); tympanum-eye length (TYE, from posterior border of orbit to anterior border of tympanum), snout length (ES, from anterior border of orbit to tip of snout), eye-nostril length (EN, from anterior border of orbit to the midpoint of posterior border of nostril), and toe lengths (from tip of toe, to the junction with the adjacent digit, excluding the claw). Supralabial and infralabial scales were counted from the gape of the lips to the rostral and mental scales respectively. Ventrals included all scales from the scale posterior to the postmental to the last scale bordering the vent, counted along the ventral midline. Paravertebral scales are between postparietal / nuchal (included) to the level of the posterior margin of the thigh in a straight line immediately left of the vertebral column. Subdigital lamellae on toe IV from the first proximal enlarged lamellae wider than the width of the largest palm scale to the distal-most lamella at the base of the claw. Total number of longitudinal scale rows was counted around the midbody.

Geographic coordinates of the skink's localities were recorded with a GPS (WGS 84 datum) and mapped with ARC MAP 10.

\section{Taxonomy}

Eutropis tytleri (Theobald, 1868)

(Figs. 1-3, 6, 7; Tables 1-3)

Scincus tytleri Theobald, 1868

Mabuia tytleri - Boulenger 1887

Mabuya tytleri - Smith 1935

Eutropis tytleri - Mausfeld and Schmitz 2003

Holotype. Adult male, ZSI 2273 [fide Das et al. (1998)], SVL $153.7 \mathrm{~mm}$, collected from Andamans, India, by Lt. Col. Robert Christopher Tytler [a handwritten note "confirmed as a type by Dr. Malcolm Smith" on the original label is present].

Other specimens $(\boldsymbol{n}=4)$. ZSI 2371, 2296, 4624; CSPT/L-33a, collected from Andamans, India: collector and date unknown.

Diagnosis. A large species of Eutropis from the Andaman Islands, SVL 125.0-153.7 mm; tail long, about 1.5-2.2 times as long as the body; prefrontals and supranasals in contact with each other; temporals smooth; nuchals in a single pair; tympanic opening relatively large; as large 


\section{Plate 12}
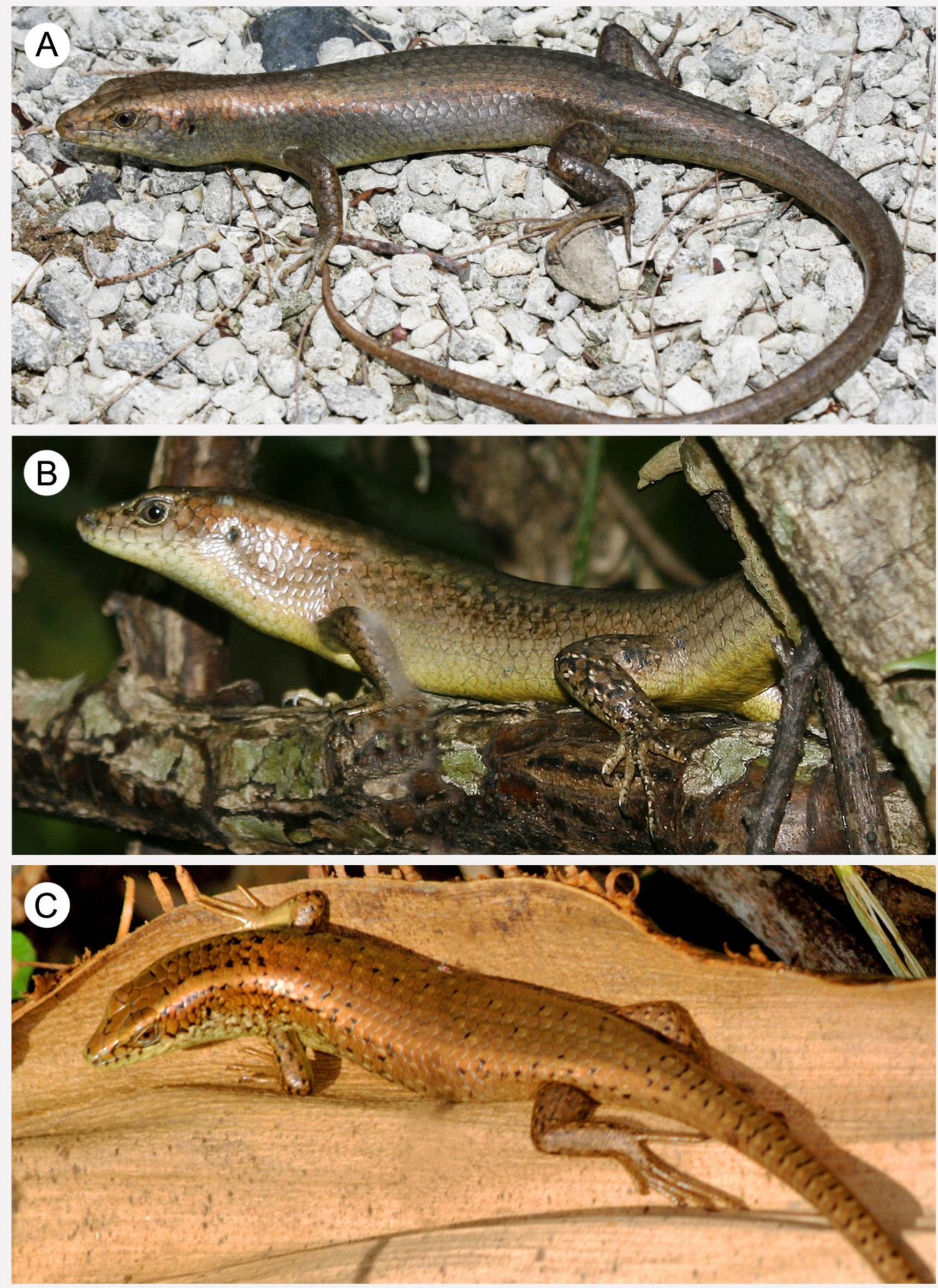

Figure 1. Eutropis tytleri in life (not collected) from (A) Long Island, (B) South Andaman, and (C) Rutland in Andaman Islands. Photograph (C) S.R. Chandramouli 


\section{Plate 13}

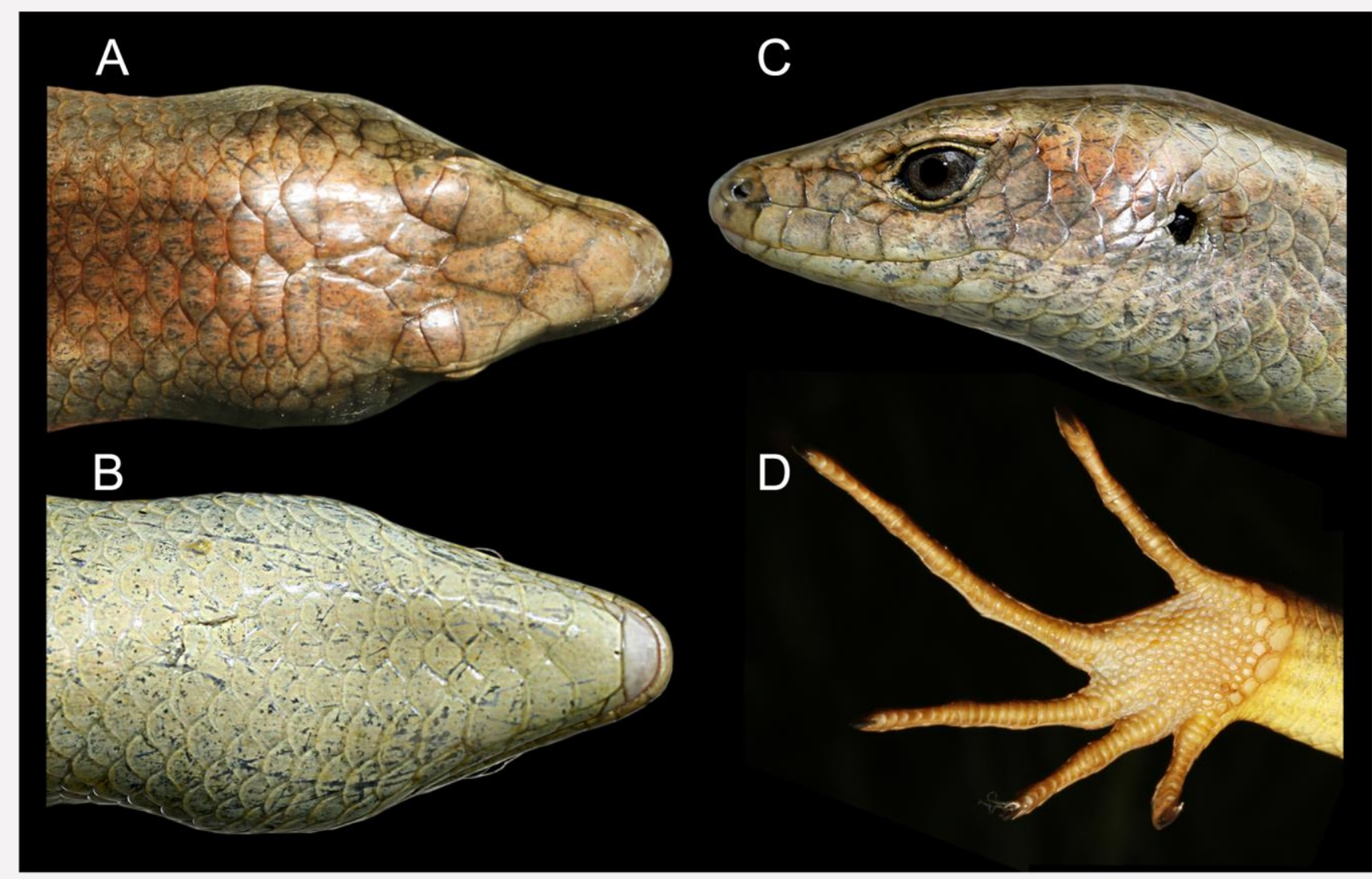

Figure 2. Eutropis tytleri in life (not collected) head in (A) dorsal view, (B) ventral view, (C) lateral view, and (D) ventral view of the left foot. Photograph (C) S.R. Chandramouli

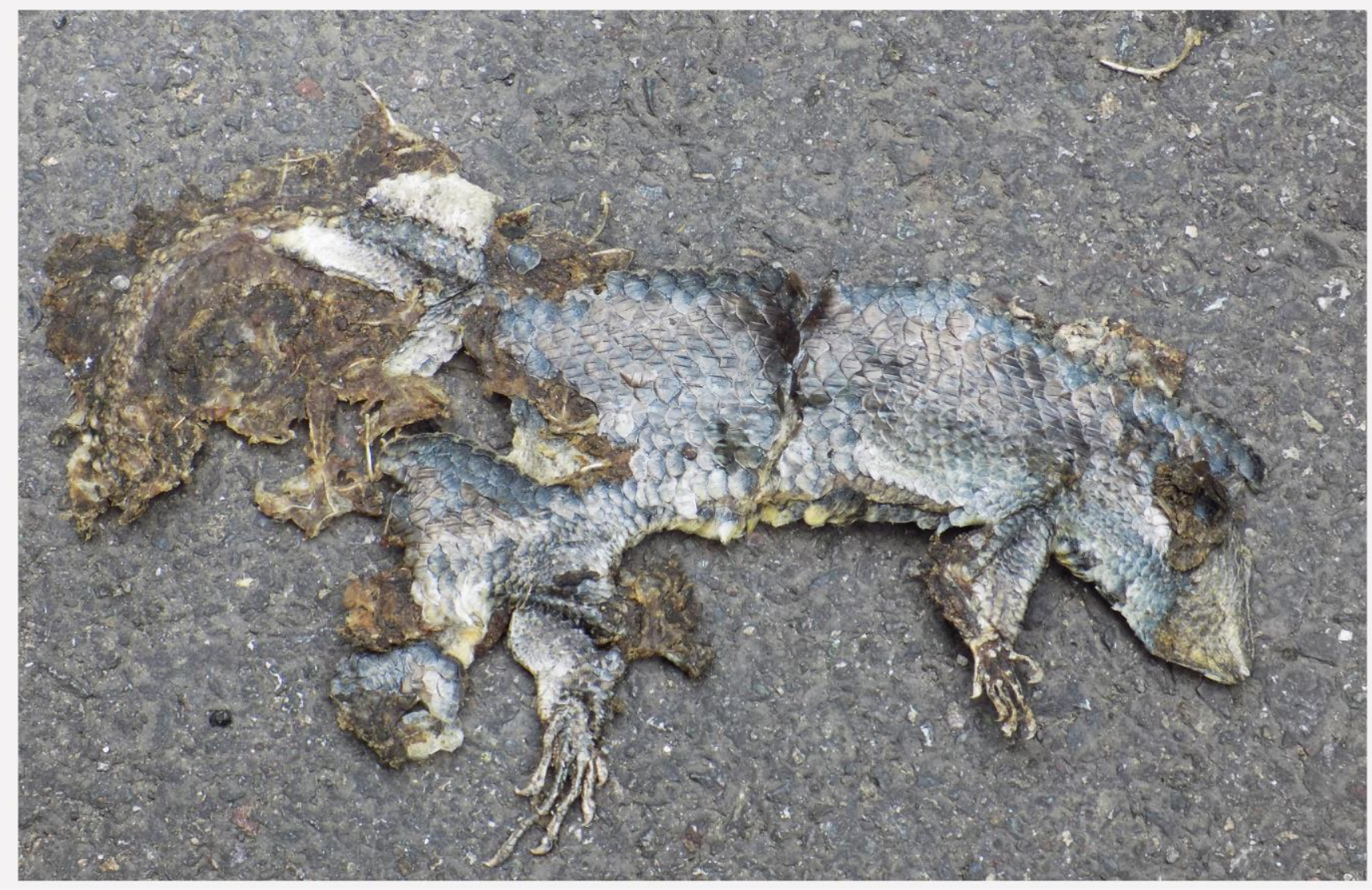

Figure 3. A road-killed individual of Eutropis tytleri from near Chidiyatapu, South Andaman Island. Photograph (C) S.R. Chandramouli 
as an adjacent lateral scale, lacking visible auricular lobules; 24-30 midbody scale rows; 40-43 paravertebrals; dorsals tricarinate; anterior genials in contact; posterior genials separated by a single scale; cheeks swollen in adult males; 50-53 ventrals; 27-30 subdigital lamellae on toe IV; dorsum uniform bronze brown with a greenish yellow venter.

Redescription of holotype. Meristic characters of the holotype (ZSI 2273). Male, SVL 153.7 $\mathrm{mm}$. Head moderately large (HL $26.1 \%$ of SVL), narrow (HW $62.8 \%$ of HL, HW $16.4 \%$ of SVL), indistinct from neck; snout short (ES $32.7 \%$ of HL, ES $52.0 \%$ of HW), slightly concave in lateral profile; rostral shield large, hemispherical, visible from above, posterior margin of midpoint concave; frontonasal not contacting rostral; frontonasal wide, lateral border touching first loreal; prefrontals in broad contact, separating frontal and frontonasal, length equals maximum frontonasal length, laterally contacting both loreal scales, posterior border contacting first supraciliary, first two supraoculars and frontal; frontal large, elongate, subtriangular, bluntly pointed posteriorly, length equal to frontoparietals and interparietal combined; frontoparietals two, in contact, larger than interparietal; parietals large and completely separated by interparietal, contacting pretemporal scales anterolaterally; single pair of nuchals, not overlapping behind interparietal. Nostril large and placed in centre of nasal; supranasal single; loreals two, anterior contacting nasal, supranasal, frontonasal, prefrontal, posterior loreal, and second \& third supralabials; posterior slightly longer than anterior loreal in the longitudinal axis, contacting prefrontal, first supracilliary, third supralabial, and forth supralabials slightly; presuboculars two; eye large (ED $21.2 \%$ of HL; considerably smaller than TYE), pupil rounded; interorbital distance broad; postoculars four, small; Supraoculars five, all wide, second longest in the longitudinal axis and widest in the transverse axis, $1^{\text {st }}$ supraocular in contact with prefrontal, $2^{\text {nd }}$ in contact with prefrontal, frontal, and frontoparietal, $3^{\text {rd }}$ in contact with frontoparietal, $4^{\text {th }}$ in contact with frontoparietal and parietal; $5^{\text {th }}$ in contact with parietal; supraciliaries six; eyelid moveable, window divided into several tall rectangular scales. Supralabials seven, fifth largest, at the mid orbit position, and contacting granular scales of lower eyelid; pretemporals three; primary temporals three, secondary temporals four; infralabials seven; ear opening small (approximately one quarter ED), deep, near round. Mental large; postmental single, large; two pairs of chin shield, first pair slightly meeting in midline, first chinshield in contact with first and second infralabial scales, the second pair in contact with second and third infralabials.

With the exception of head shields and nuchals, all dorsal scales are tricarinate, on some scales the median keel is not prominent; all scales imbricate; scales on dorsal surface of thigh moderately tricarinate; body slender, elongate; midbody scale rows 24 ; paravertebral scales 40; ventrals 51; preanal scales enlarged, four.

Forelimbs short, hind limbs relatively long (FEL $14.2 \%$ of SVL, TBL $16.0 \%$ of SVL); thigh shorter (FEL $89.0 \%$ of TBL); dorsal surfaces of fore and hind limbs moderately tricarinate; subdigital lamellae of toes I-V: 11, 18, 25, 28 and 15 respectively; relative length of fingers IV $>$ III $>$ II $>$ V $>$ I; those of toes IV $>$ III $>$ V > II $>$ I. Tail broken, median scale row of subcaudals of original tail horizontally elongate and entire.

Variation. See Tables $1 \& 2$.

Coloration. In the preserved holotype, dorsal head, body and limbs appear uniform olive green, limbs darker. Venter lighter. In life (not collected), dorsal head, body and limbs are uniform bronze brown, with scattered black spots on the neck, lateral body, on the limbs, and tail. Lateral body lighter than the dorsum in colour, temporal area pinkish. Throat lemon green and venter light yellow.

Distribution. During the present study, $E$. tytleri was recorded from different localities throughout the Andaman Islands (Table 3).

Natural History. E. tytleri is the largest skink species found within the Indian subcontinent. It is crepuscular in habits and is often seen emerging in the evening hours. Diurnal activity is relatively less and is often restricted to basking in the morning and foraging until mid-day.

Based on personal observations, it feeds on insects, frogs and smaller reptiles; and tends to be bulkier on certain small islands, possibly due to the lack of competition from other similar sized lizards.

Unlike other Eutropis species, it is arboreal to some extent and can often be seen on tree trunks till a height of about $3 \mathrm{~m}$ above the ground. Unlike other skinks, it can be seen moving around actively until about 20:00 h, well 
after the dark. Individuals of $E$. tytleri were observed to suffer mortality due to road traffic in reserve forests on three occasions.

\section{Eutropis andamanensis (Smith, 1935)}

(Figs. 4-7; Tables 1-3)

Mabuya andamanensis Smith, 1935

Mabuya andamanensis - Greer et al. 2000

Eutropis andamanensis — Mausfeld et al. 2002

Syntypes (ex. 2). Adult female, ZSI 15084, SVL $102.1 \mathrm{~mm}$, collected from Andamans, India, by C.G. Rogers; BMNH 1946.8.3.62 (formerly ZSI 14658), SVL not measured, other data same as ZSI 15084.

Diagnosis. A medium sized species of Eutropis from the Andaman Islands, SVL 75.0-115.0 $\mathrm{mm}$; tail relatively short, about 1.4 times as long as the body; the two prefrontals and supranasals separated from each other; temporals keeled; nuchals in a single pair; tympanic opening relatively large; larger than an adjacent lateral scale, with three small, rounded auricular lobules; 28-30 midbody scale rows; 36-40 paravertebrals; dorsals pentacarinate; anterior genials in contact; posterior genials separated by a single scale; 48-56 ventrals; $26-28$ subdigital lamellae on toe IV; dorsum uniform bronze brown with a greenish yellow venter.

Redescription of a syntype. Meristic and morphometric characters of the syntype (ZSI $15084)$ are presented, the other syntype (BMNH 1946.8.3.62) not examined. Female, SVL 102.1 $\mathrm{mm}$. Head moderately large (HL $25.6 \%$ of SVL), narrow (HW 59.4\% of HL, HW $15.2 \%$ of SVL), indistinct from neck; snout short (ES $31.8 \%$ of $\mathrm{HL}$, ES $53.5 \%$ of $\mathrm{HW}$ ), slightly concave in lateral profile; rostral shield large, hemispherical, visible from above, posterior margin of midpoint concave; frontonasal contacting rostral; frontonasal wide, lateral border touching first loreal; prefrontals not in contact, not separating frontal and frontonasal, length less than frontonasal length, laterally contacting both loreal scales, posterior border contacting first supraciliary, first supraocular and frontal; frontal large, elongate, subtriangular, bluntly pointed posteriorly, length greater than frontoparietals and interparietal combined; frontoparietals two, in contact, larger than interparietal; parietals large and posteriorly not separated by interparietal, contacting pretemporal scales anterolaterally; single pair of nuchals, overlapping middorsally. Nostril large and placed in centre of nasal; supranasal single; loreals two, anterior contacting nasal, supranasal, frontonasal, prefrontal, posterior loreal, and second supralabial; posterior longer than anterior loreal in the longitudinal axis, contacting prefrontal, first supracilliary, third and fourth supralabials; presuboculars two; eye large (ED $25.7 \%$ of HL; slightly smaller than TYE), pupil rounded; interorbital distance broad; postoculars three, small; Supraoculars four, all wide, second longest in the longitudinal axis and widest in the transverse axis, $1^{\text {st }}$ supraocular in contact with prefrontal and frontal, $2^{\text {nd }}$ in contact with frontal, and frontoparietal, $3^{\text {rd }}$ in contact with frontoparietal, $4^{\text {th }}$ in contact with frontoparietal and parietal; supraciliaries six; eyelid moveable, window divided into several tall rectangular scales.

Supralabials nine, sixth largest, at the mid orbit position, and contacting granular scales of lower eyelid; pretemporals three; primary temporals two, secondary temporals three; infralabials eight; ear opening small (approximately one sixth ED), deep, near round. Mental large; postmental single, large; two pairs of chin shield, first pair broadly meeting in midline, first chinshield in contact with second and third infralabial scales, the second pair in contact with third and fourth infralabials.

Nuchals carinate; all dorsal scales are strongly quinquecarinate; all scales imbricate; body slender, elongate; midbody scale rows 30 ; paravertebral scales 37 ; ventrals 56 ; preanal scales enlarged, four.

Forelimbs short, hind limbs relatively long (FEL $17.0 \%$ of SVL, TBL $17.7 \%$ of SVL); thigh slightly shorter (FEL $96.1 \%$ of TBL); dorsal surfaces of fore and hind limbs strongly quinquecarinate; subdigital lamellae of toes I-V: $9,17,23,29$ and 17 respectively; relative length of fingers IV > III > II > V > I; those of toes IV $>$ III $>$ V > II > I. Tail complete, median scale row of subcaudals of original tail entire.

Variation. See Tables $1 \& 2$.

Coloration. In the preserved syntype, dorsal head, body and limbs uniform dark greyish brown, limbs darker. A narrow chestnut brown broken pair of lateral lines starting from back of the eyes until midbody, disappear afterwards. Venter light yellow.

In life (not collected), dorsum rich bronze brown with two dark brown lateral bands along the body from post orbital region till the tail. Intensity of the lateral bands varies with age, 


\section{Plate 14}

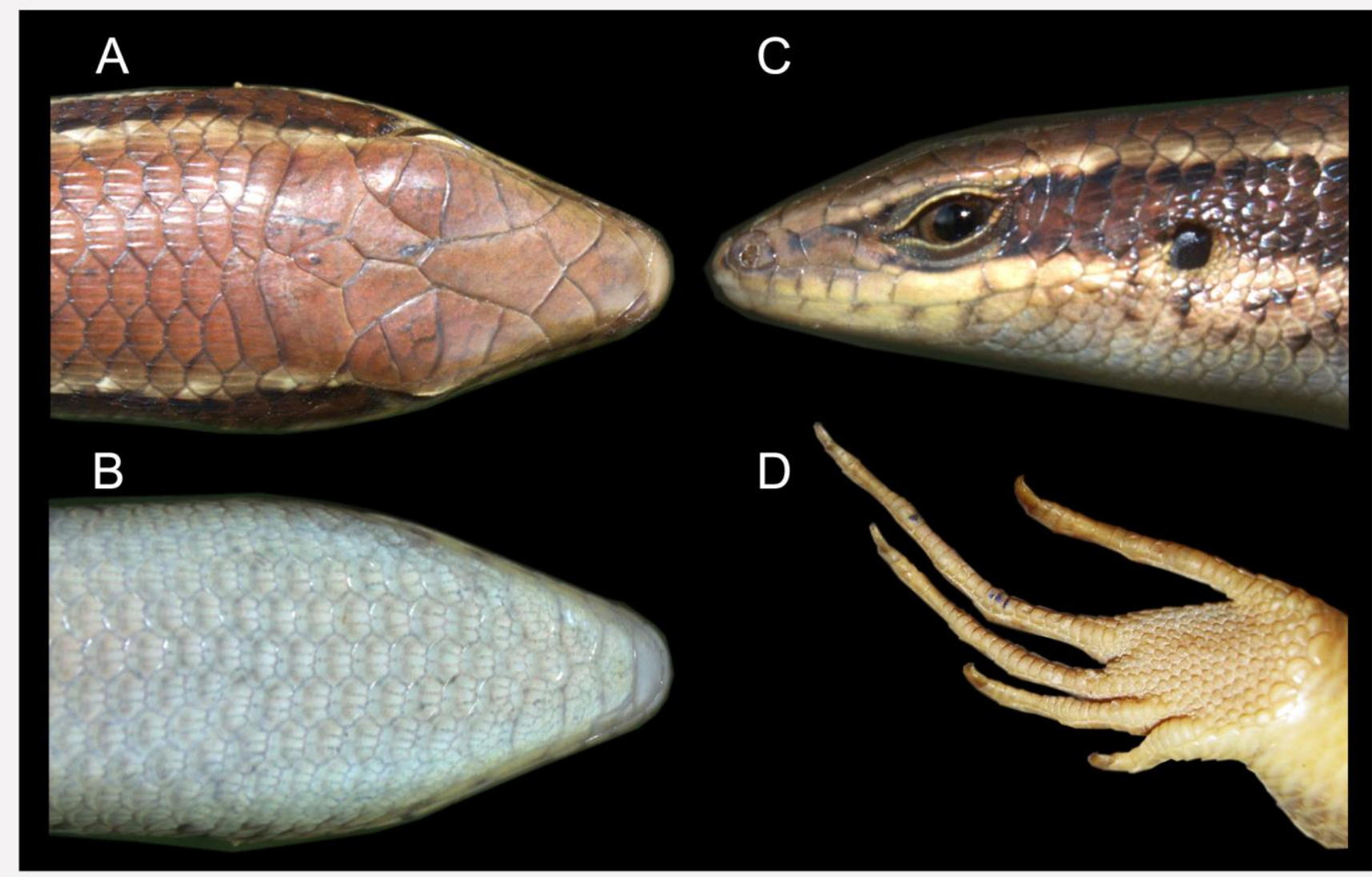

Figure 4. Eutropis andamanensis in life (not collected) head in (A) dorsal view, (B) ventral view, (C) lateral view, and (D) ventral view of the left foot. Photograph (C) S.R. Chandramouli

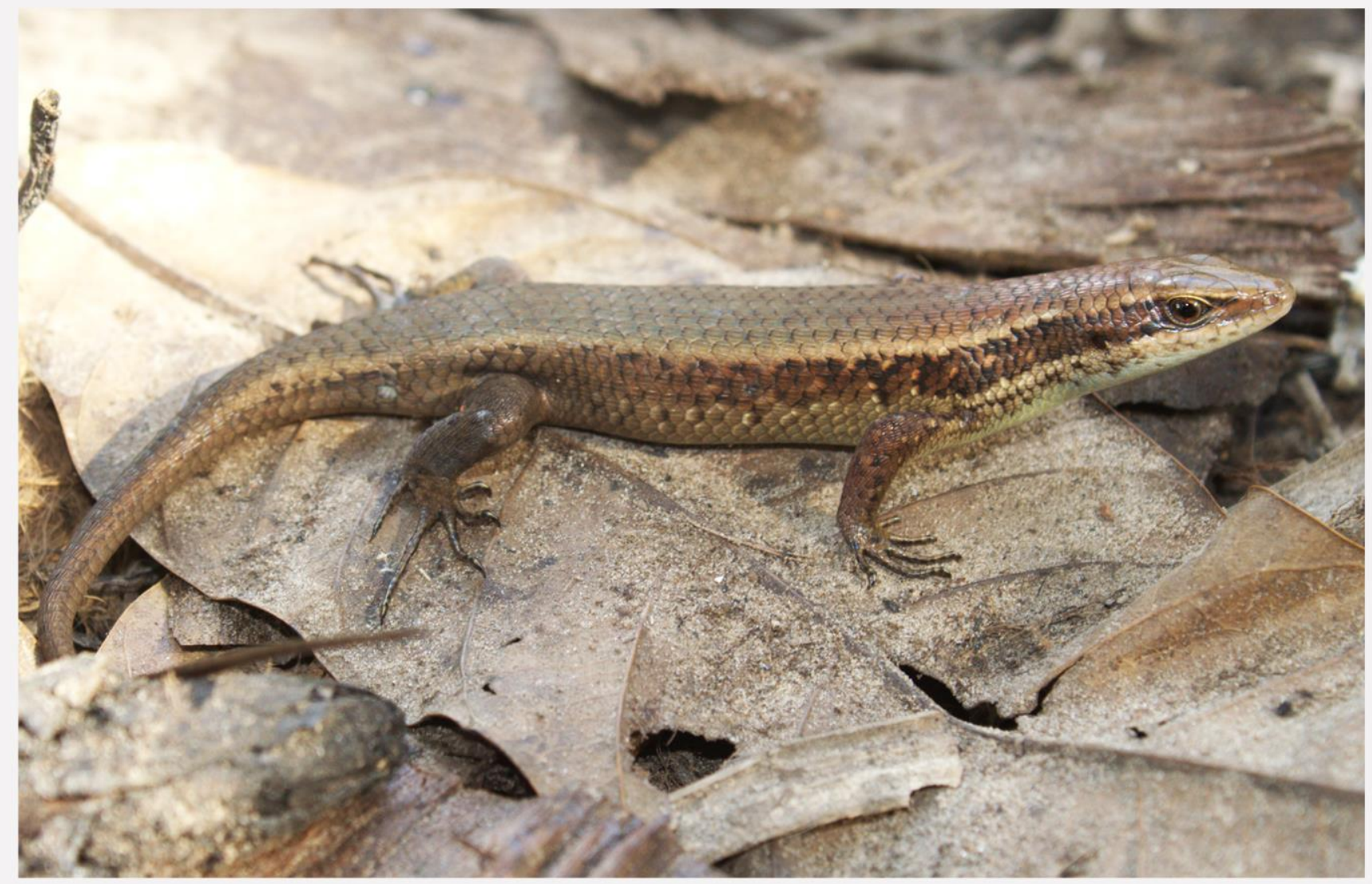

Figure 5. Eutropis andamanensis in life (not collected) from the Andaman Islands.

Photograph (C) S.R. Chandramouli 
with the bands being distinct and dark in young individuals while broken with intermittent white spots in aged individuals. Upper lip, lower lateral body and venter cream coloured.

Distribution. During the present study, $E$. andamanensis was recorded from different localities throughout the Andaman Islands (Table 3).

Natural History. A diurnal species which has, at times, been seen active till 18:30 $\mathrm{h}$ at the dusk. Predominantly terrestrial and often seen on the ground in leaf-litter, but occasionally seen on low-lying tree trunks to a height of about $1.5 \mathrm{~m}$ above the ground. Based on personal observations, this skink feeds on insects, worms, small frogs and crustaceans.

\section{Discussion}

The information presented here on taxonomy, morphology, behaviour and natural history of $E$. tytleri and $E$. andamanensis adds significantly to our existing knowledge on these species, which were described in the $1860 \mathrm{~s}$ and 1930s respectively. Until now, only anecdotal notes have been available on these species based on older literature. Stoliczka (1870) mentions certain unusually large specimens of "Tiliqua carinata" collected from the Andaman Islands by Roepstorff with a long tail, which were referred to E. tytleri by Smith (1935).

These species still remain poorly known due to the lack of sufficient field records and data, and hence, their conservation status assessments remain yet to be assessed (IUCN 2020). Das (2002) erroneously illustrated $E$. andamanensis as E. tytleri in his species accounts. The identity of the individuals and specimens described and illustrated here were confirmed by comparing their respective type specimens (Fig. 6).

Both these species seem to be equally widespread within the Andaman archipelago (Fig. $7 \&$ Table 3).

Table 1. Morphometric (in $\mathrm{mm}$ ) and meristric character comparisons of Scincus tytleri Theobald, 1868 holotype and Mabuya andamanensis Smith, 1935 synype, and other specimens from Andamans; "—” = not measured.

\begin{tabular}{lcccc}
\hline & \multicolumn{2}{c}{ E. tytleri } & \multicolumn{2}{c}{ E. andamanensis } \\
\cline { 2 - 5 } Character & Holotype & Other & Syntype & Other \\
Sex & ZSI 2273$)$ & preserved $(n=4) \&$ live $(n=7)$ & (ZSI 15084) & live $(n=6)$ \\
\cline { 2 - 5 } SVL & male & both & female & both \\
Head length (HL) & 153.7 & $125.8-153.0$ & 102.1 & $75.0-115.0$ \\
Head width (HW) & 40.1 & $21.3-25.6$ & 26.1 & $12.5-20.1$ \\
Axilla-groin distance (AG) & 25.2 & $18.7-22.3$ & 15.5 & $11.9-20.8$ \\
Eye-nostril length (EN) & 81.2 & $57.5-80.0$ & 42.9 & $30.0-50.0$ \\
Snout length (ES) & 9.2 & $9.2-11.2$ & 5.7 & $6.1-8.5$ \\
Tympanum-eye (TYE) & 13.1 & $10.6-14.3$ & 8.3 & $8.2-12.4$ \\
Orbit diameter (ED) & 12.0 & $10.1-13.4$ & 7.1 & $7.2-9.9$ \\
Thigh length (FEL) & 8.5 & $5.4-7.2$ & 6.7 & $3.5-6.8$ \\
Shank length (TBL) & 21.9 & $18.2-23.9$ & 17.4 & $12.2-22.3$ \\
Tail length (TAL) & 24.6 & $19.8-22.4$ & 18.1 & $12.5-23.5$ \\
Midbody scale rows & - & $220.0-290.0$ & 30 & $120.0-175.0$ \\
Nuchal pairs & 24 & $24-26$ & 1 & $28-30$ \\
Ventrals & 1 & 1 & 56 & 1 \\
Lamellae on 4 th toe & 51 & $48-53$ & 29 & $48-55$ \\
Paravertebral scales & 28 & $24-30$ & 37 & $26-28$ \\
\hline
\end{tabular}

Table 2. Diagnostic characters of Eutropis tytleri and E. andamanensis (live and preserved) in Andaman Islands

\begin{tabular}{lcc}
\hline & E. tytleri $(n=12)$ & E. andamanensis $(n=7)$ \\
\cline { 2 - 3 } Dorsal scales & tricarinate & quinquecarinate \\
Temporal scales & smooth & keeled \\
Lateral band & invisible & visible \\
Supranasals & in contact & separated \\
Prefrontals & in broad contact & separated \\
Prefrontals in contact with & $1^{\text {st }} \& 2^{\text {nd }}$ supraocular & $1^{\text {st }}$ supraocular only \\
Frontal in contact with & $2^{\text {nd }}$ supraocular only & $1^{\text {st }} \& 2^{\text {nd }}$ supraocular \\
Parietals & completely separated & In contact behind interparietal \\
Midbody scale rows & $24-26$ & $28-30$ \\
\hline
\end{tabular}




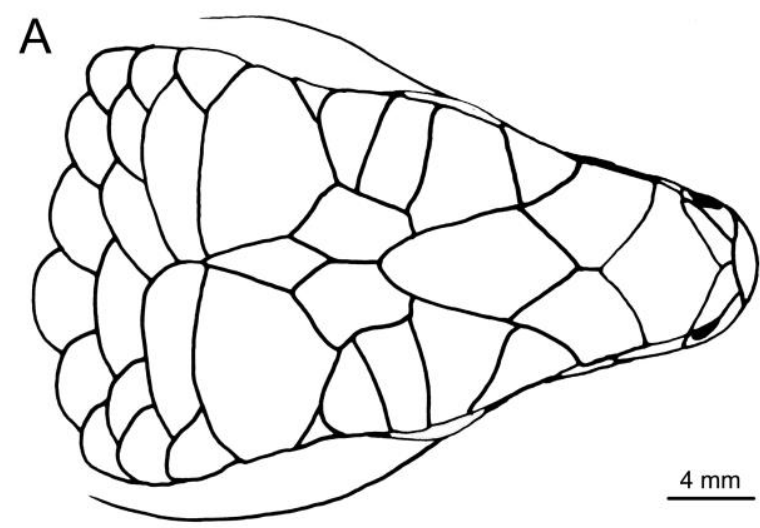

B

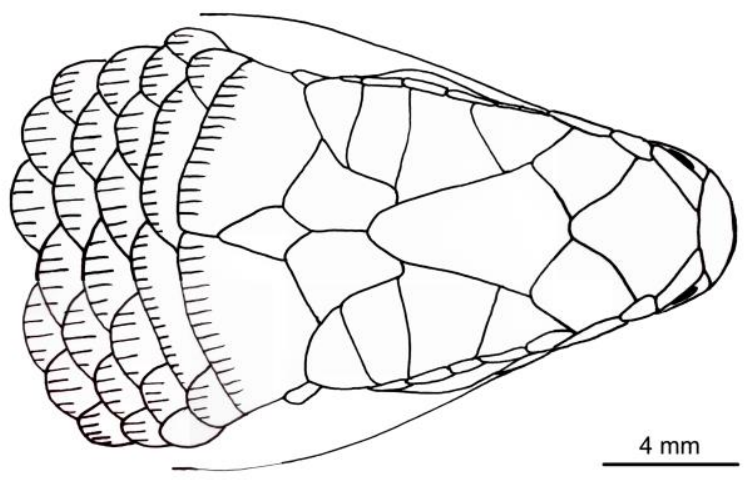

C

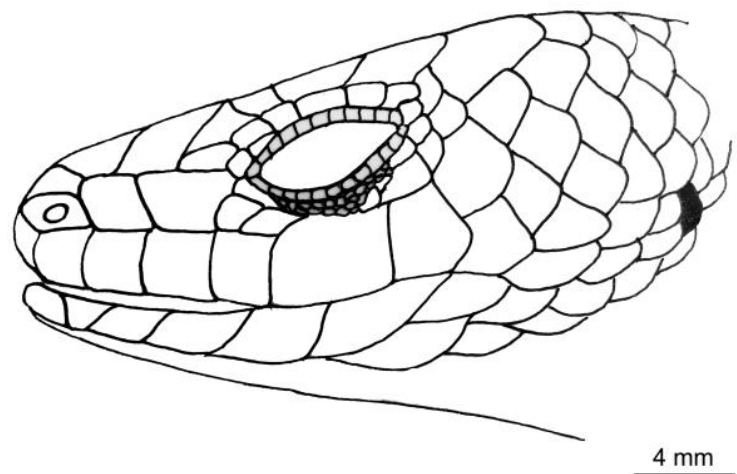

$\mathrm{D}$

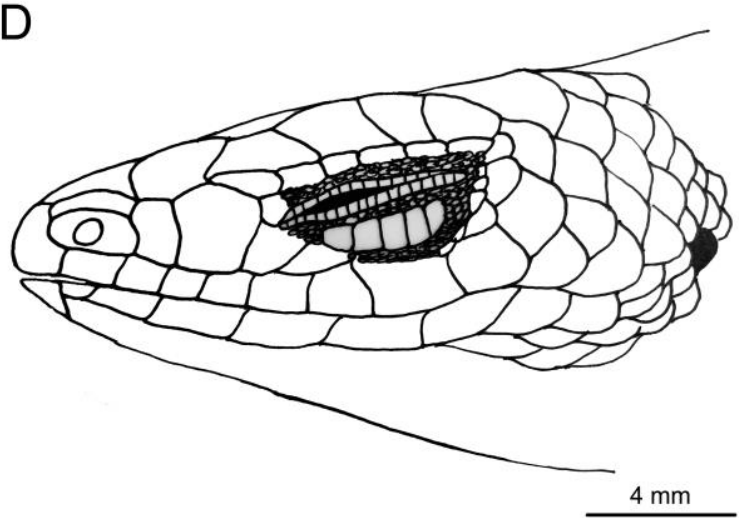

Figure 6. Head in dorsal and lateral views of (A, C) the holotype of Eutropis tytleri (ZSI 2273) and (B, D) syntype of E. andamanensis (ZSI 15084). Illustration (C) A.A.T. Amarasinghe

E. andamanensis is more common and can be seen abundantly whereas E. tytleri is relatively rare and less abundant. $E$. andamanensis is relatively more tolerant to human mediated habitat disturbances than $E$. tytleri, which is a more forest dependent species. There seems to be some degree of ecological niche partitioning between these two relatively large bodied skinks.

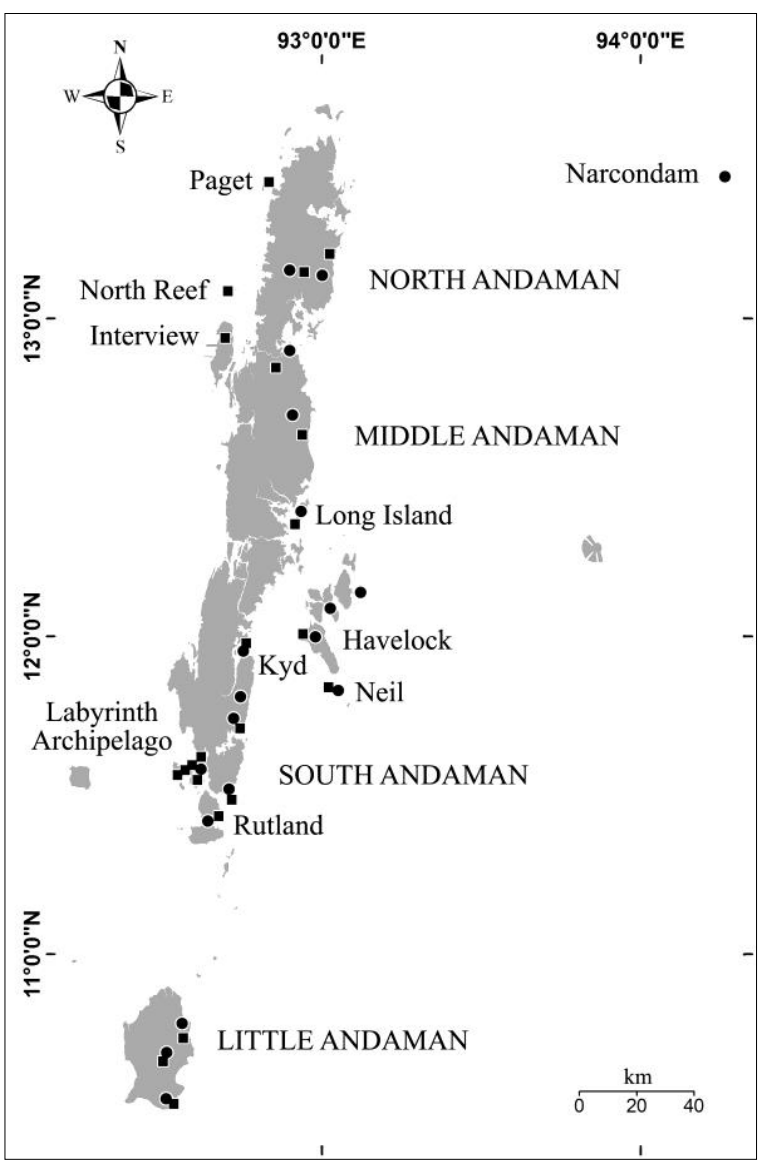

Figure 7. Current distribution of Eutropis tytleri (in circles) and E. andamanensis (in squares) in the Andaman Islands based on known locality records.

Among them, E. tytleri has a larger body size in comparison to E. andamanensis and is more arboreal in habit than the latter. Likewise, E. tytleri shows a crepuscular activity by being more active during twilight hours than during the day. On the other hand, E. andamanensis seldom ventures out after sunset.

E. andmanensis seems to undergo a gradual ontogenetic colour change as the intensity of the dark lateral bands seem to fade with age: young individuals have much darker and more legible bands than old ones, which have intermixed white spots on the dark bands along the lateral sides of the body. Such a phenomenon has not 
been recorded in E. tytleri. Road traffic in forest reserves has been identified as a potential threat to these skinks (Fig. 3). A precise distribution map for these species presented here based on current and confirmed past records will aid in their conservation status assessments. Locality details are listed in Table 3.

Table 3. Locality records of Eutropis tytleri and E. andamanensis in the Andaman Islands based on the present study and literature.

\begin{tabular}{|c|c|c|c|c|c|}
\hline Species & Locality, Island & Lat. & Long. & Alt. (m) & Source \\
\hline both species & Mt. Harriet NP, South Andaman & 11.7207 & 92.7336 & 362 & present study \\
\hline both species & Chidiyatapu, South Andaman & 11.4917 & 92.7088 & 77 & present study \\
\hline both species & Wandoor, South Andaman & 11.6154 & 92.6194 & 3 & present study \\
\hline both species & Bada Khadi, Rutland & 11.4291 & 92.6649 & 2 & present study \\
\hline both species & Kyd, Kyd Island & 11.9663 & 92.7546 & 6 & present study \\
\hline both species & Sitapur, Neil Island & 11.8302 & 93.0342 & 11 & present study \\
\hline both species & Radhanagar, Havelock & 12.0085 & 92.9638 & 43 & present study \\
\hline both species & Harminder Bay, Little Andaman & 10.5334 & 92.5353 & 24 & present study \\
\hline both species & Krishnanallah, Little Andaman & 10.6776 & 92.5087 & 153 & present study \\
\hline both species & Dinghi Ghat, Little Andaman & 10.7375 & 92.5673 & 16 & present study \\
\hline both species & Long Island & 12.3693 & 92.9193 & 26 & present study \\
\hline both species & Cutbert Bay, Middle Andaman & 12.6359 & 92.9560 & 22 & present study \\
\hline both species & Mayabunder, Middle Andaman & 12.8474 & 92.8565 & 20 & present study \\
\hline both species & Kishori Nagar, North Andaman & 13.1485 & 92.9427 & 99 & present study \\
\hline both species & Lamia Bay, North Andaman & 13.1983 & 93.0367 & 6 & present study \\
\hline both species & Interview & 12.9425 & 92.6978 & 64 & present study \\
\hline E. andamanensis & Tarmugli & 11.5734 & 92.5519 & 29 & present study \\
\hline E. andamanensis & Alexandra & 11.5785 & 92.6129 & 46 & present study \\
\hline E. andamanensis & Redskin & 11.5709 & 92.5929 & 36 & present study \\
\hline E. andamanensis & Chester & 11.5832 & 92.5782 & 0 & present study \\
\hline E. andamanensis & Grub & 11.5894 & 92.5936 & 0 & present study \\
\hline E. andamanensis & Paget & 13.4301 & 92.8324 & 34 & present study \\
\hline E. andamanensis & North Reef & 13.0899 & 92.7013 & 18 & present study \\
\hline E. tytleri & Narcondam & 13.4491 & 94.2638 & 13 & Raman et al. (2013) \\
\hline E. tytleri & Inglis & 12.1399 & 93.0940 & 7 & Sivaperuman (2014) \\
\hline E. tytleri & John Lawrance & 12.0975 & 93.0411 & 5 & Sivaperuman (2014) \\
\hline
\end{tabular}

\section{Acknowledgments}

We thank the Department of Environment and Forests, Andaman and Nicobar Islands for permission to SRC (permit no: CWLW/WL/134/(J)/Folder/417) for conducting this study and for the infrastructure provided; K.V. Devi Prasad and the faculty of the Department of Ecology and Environmental Sciences and the Department of Ocean studies and Marine Biology, Pondicherry University for the support extended, the Mohamed bin Zayed Species Conservation fund for a grant (\#14058387) which partly facilitated this study. We also thank the former Director, K. Venkataraman (Zoological Survey of India) for granting research permission to AATA. In particular we thank K. Chandra (Director) K. C. Gopi (officer-in-charge, FPS Building, ZSI, Kolkata), K. A. Subramanian (officer-in-charge, Technical Section, ZSI) for their help throughout the permitting application process. K. Deuti, S.
Raha, P.G.S. Sethy, P. Bag, and S. Debnath are also acknowledged for assisting us while examining collections in ZSI; Officers at the Chennai Snake Park Trust facilitated the study of preserved specimens under their care. We thank Jakob Hallermann (Universität Hamburg, Germany) and Philip Bowles (IUCN) for the review of the manuscript and critical comments. Finally, we thank J. Supriatna and the staff of the Research Center for Climate Change, University of Indonesia, for their support.

\section{Literature Cited}

Amarasinghe, A.A.T., S.R. Chandramouli, K. Deuti, P.D. Campbell, S.M. Henkanaththegedara et al. (2020). A revision of Eutropis rudis (Boulenger, 1887), resurrection of E. lewisi (Bartlett, 1895) and description of a new species (Squamata: Scincidae) from Great Nicobar. Taprobanica, 9 (1): 12-22. 
Boulenger, G.A. (1887). Catalogue of the Lizards in the British Museum (Nat. Hist.) III. Lacertidae, Gerrhosauridae, Scincidae, Anelytropsidae, Dibamidae, Chamaeleontidae, London: $575 \mathrm{pp}$.

Daniel, J.C. (2002). The book of Indian reptiles and amphibians. Oxford University Press, London: $238 \mathrm{pp}$.

Das, I., B. Dattagupta, and N.C. Gayen (1998). History and catalogue of reptile types in the collection of the Zoological Survey of India. Journal of South Asian Natural History, 3 (2): $1-52$.

Das, I. (1999). Biogeography of the amphibians and reptiles of the Andaman and Nicobar Islands, India. In: Ota, H. (ed.) Tropical Island herpetofauna: origin, current diversity and current status. Elsevier: 43-77.

Das, I. (2002). Snakes and other reptiles of India. New Holland, London: 144 pp.

Das, I. and A. Das (2018). A naturalists guide to the reptiles of India, Bangladesh, Bhutan, Nepal, Pakistan and Sri Lanka. John Beaufoy Publishers, Oxford, London: 176 pp.

Hall, R. (1997). Cenozoic plate tectonic reconstructions of SE Asia. In: Fraser, A.J., S.J. Mathews, R.W. Murphy (eds.). Petroleum geology of Southeast Asia. Geological Society of London special publication: 126: 11-23.

IUCN (2020). The IUCN red list of threatened species <www.iucnredlist.org〉. Accessed on 27 Apr 2020.

Mausfeld, P., A. Schmitz, W. Böhme, B. Misof, D. Vrcibradic et al. (2002). Phylogenetic affinities of Mabuya Atlantica Schmidt, 1945, endemic to the Atlantic Ocean Archipelago of Fernando de Noronha (Brazil): necessity of partitioning the genus Mabuya Fitzinger, 1826 (Scincidae: Lygosominae). Zoologischer Anzeiger, 241 (3): 281-293.
Mausfeld, P. and A. Schmitz (2003). Molecular phylogeography, intraspecific variation and speciation of the Asian scincid lizard genus Eutropis Fitzinger, 1843 (Squamata: Reptilia: Scincidae): taxonomic and biogeographic implications. Organisms diversity and evolution, 3 (3): 161-171.

Raman, T.S., D. Mudappa, T. Khan, U. Mistry, A. Saxena et al. (2013). An expedition to Narcondam: observations of marine and terrestrial fauna including the island endemic hornbill. Current Science, 105 (3): 346-360.

Sivaperuman, C. (2014). Faunal Resources in the Ritchie's Archipelago, Andaman and Nicobar Islands. Zoological Survey of India, Occasional papers, 360: $16 \mathrm{pp}$.

Smith, M.A. (1935). The fauna of British India, including Ceylon and Burma. Reptiles and Amphibia, Vol. II. Sauria. Taylor and Francis, London: $440 \mathrm{pp}$.

Stoliczka, F. (1870). Observations on some Indian and Malayan Amphibia and Reptilia. Journal of Asiatic Society Bengal, 39 (3): 134-228.

Theobald, W. (1868). Catalogue of reptiles in the Museum of the Asiatic Society of Bengal. Journal of Asiatic Society Bengal, 37 (2): 2324.

Uetz, P., S. Cherikh, G. Shea, I. Ineich, P.D. Campbell et al. (2019). A global catalog of primary reptile type specimens. Zootaxa, 4695 (5): 438-450. 